\title{
Ice mass-balance buoys: a tool for measuring and attributing changes in the thickness of the Arctic sea-ice cover
}

\author{
Jacqueline A. RICHTER-MENGE, ${ }^{1}$ Donald K. PEROVICH, ${ }^{1}$ Bruce C. ELDER, ${ }^{1}$ \\ Keran CLAFFEY, ${ }^{1}$ Ignatius RIGOR, ${ }^{2}$ Mark ORTMEYER ${ }^{2}$ \\ ${ }^{1}$ US Army Cold Regions Research and Engineering Laboratory, 72 Lyme Road, Hanover, NH 03755-1290, USA \\ E-mail: Jacqueline.A.Richter-Menge@erdc.usace.army.mil \\ ${ }^{2}$ Polar Science Center, Applied Physics Laboratory, University of Washington, 1013 NE 40th Street, Seattle,
} WA 98105-6698, USA

\begin{abstract}
Recent observational and modeling studies indicate that the Arctic sea-ice cover is undergoing significant climate-induced changes, affecting both its extent and thickness. The thickness or, more precisely, the mass balance of the ice cover is a key climate-change indicator since it is an integrator of both the surface heat budget and the ocean heat flux. Accordingly, efforts are underway to develop and deploy in situ observing systems which, when combined with satellite remote-sensing information and numerical models, can effectively monitor and attribute changes in the mass balance of the Arctic sea-ice cover. As part of this effort, we have developed an autonomous ice mass-balance buoy (IMB), which is equipped with sensors to measure snow accumulation and ablation, ice growth and melt, and internal ice temperature, plus a satellite transmitter. The IMB is unique in its ability to determine whether changes in the thickness of the ice cover occur at the top or bottom of the ice cover, and hence provide insight into the driving forces behind the change. Since 2000, IMBs have been deployed each spring from the North Pole Environmental Observatory and in several other areas, including a few in the Beaufort Sea and Central Basin. At this point, the collective time series is too short to draw significant and specific conclusions regarding interannual and regional variability in ice mass balance. Comparisons of available data indicate that ice surface ablation is greater in the Beaufort region $(67-80 \mathrm{~cm})$, relative to the North Pole $(0-30 \mathrm{~cm})$, consistent with a longer period of melt in the more southerly location. Ablation at the bottom of the ice $(22 \mathrm{~cm})$, maximum ice thickness $(235 \mathrm{~cm})$ and maximum snow depth $(28 \mathrm{~cm})$ were comparable in the two regions.
\end{abstract}

\section{INTRODUCTION}

Recent studies indicate that the Arctic sea-ice cover is undergoing significant climate-induced changes, affecting both its extent and thickness. For instance, satellite-derived estimates of maximum ice extent suggest a net reduction between 1978 and 1999, at an average rate of 3\% per decade (e.g. Parkinson and others, 1999; Parkinson and Cavalieri, 2002). A report by Comiso (2002) indicates an even more rapid reduction in the perennial sea-ice cover, of $9 \%$ per decade. During the summers of 2002-05, there has been an unprecedented series of extreme ice-extent minima (Stroeve and others, 2005; personal communication from J.C. Stroeve, 2006). Ice-thickness data, derived from submarine-based upward-looking sonar, also suggest a net thinning of the perennial sea-ice cover since 1958 (Rothrock and others, 1999; Wadhams and Davis, 2000; Tucker and others, 2001). Model results, used to extend these observations in both space and time, are consistent with this conclusion and further suggest that the decline in perennial ice thickness was most rapid in the 1990s (Rothrock and others, 2003). It is important that we continue and expand efforts to monitor these changes to (a) improve the fundamental understanding of the role of the sea-ice cover in the global climate system and its influence on the Arctic ecosystem and (b) take advantage of the sensitivity of the sea-ice cover as an early indicator of the magnitude and impact of climate change.

The thickness or, more precisely, the mass balance of the ice cover is a key climate-change indicator, since it is an integrator of both the surface heat budget and the ocean heat flux. If there is net warming over time, then there will be thinning of the ice. Conversely, a net cooling leads to thicker ice. The mass balance of the sea-ice cover is a function of its extent and thickness, which combine to give its volume. The extent of the sea-ice cover is effectively monitored from satellite platforms using passive microwave imagery. Monitoring changes in the ice thickness is more problematic. As with ice extent, the ideal platform for monitoring ice thickness is a satellite because it provides a full-basin perspective. Until recently, no technique had been adequately developed to obtain reliable satellite-based measurements of ice thickness. Results reported by Laxon and others (2003) and Kwok and others (2004) suggest possible breakthroughs in the use of satellite altimeter measurements of ice freeboard to determine the mean ice-thickness field and its variability. As this and other satellite-based technologies develop, we must also find ways to make more effective use of ice-thickness measurements collected from other platforms, including submarines, aircraft, sea-floor moorings and drifting buoys. While these measurement platforms have spatial limitations, they can play a central role in the validation and calibration of satellite-based instruments. Further, their capacity to collect data at higher temporal and spatial resolutions can provide information necessary to understand and attribute observed changes in the ice thickness.

This paper gives a detailed description of an ice massbalance buoy (IMB), designed to make in situ observations of changes in the mass balance of the ice cover. We 


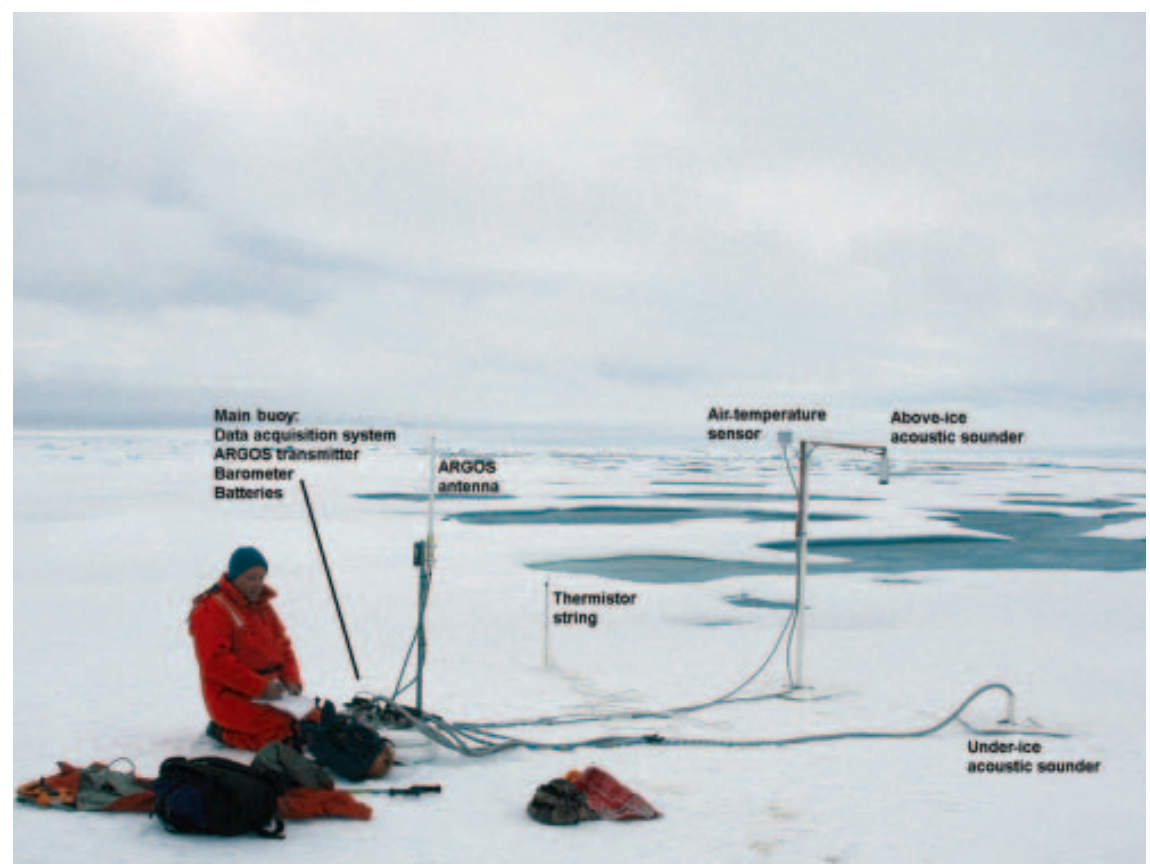

Fig. 1. IMB installed in a multi-year ice floe.

illustrate the data stream from the IMB, present a map of deployments and buoy trajectories, and discuss early results and observations.

\section{APPROACH}

Making direct measurements of the mass balance during a field experiment is straightforward. An array of stakes and thickness gauges is used to measure ablation and accumulation of ice and snow at the top and bottom of the ice cover. In spite of the importance of mass-balance measurements and the relatively simple equipment involved in making them, there are few observational results (Untersteiner, 1961; Hanson, 1965; Maykut and McPhee, 1995; Perovich and others, 1997, 2003). This is due, in large part, to the expense involved in operating a long-term drifting station.

Autonomous IMBs provide an inexpensive alternative to field campaigns (Perovich and Elder, 2001). These ice-based systems (Fig. 1) provide a means of routinely monitoring the ice mass balance at many locations for durations as long as a few years. Each drifting buoy is equipped with thermistor strings, which extend through the snow and ice cover and into the upper ocean, and acoustic sensors monitoring the position of the top and bottom surfaces of the ice. These instruments provide a time series of snow accumulation and ablation, ice mass balance, internal ice temperature fields, and temporally averaged estimates of ocean heat flux. Taken together, these data delineate whether there has been a change in the mass balance of the ice due to ice growth, surface melt, bottom ablation or snow accumulation. Observed changes can be correlated with driving forces, such as the start and duration of the summer melt season, the length of the growth season, and the ocean heat flux (Fig. 2). This information provides important insight into the driving forces behind the change. The IMBs are also equipped to measure position, sea-level pressure (SLP) and surface air temperature (SAT). The drift pattern of the buoys provides information on the circulation pattern of the sea-ice cover.
Data on SLP and SAT are designed to be compatible with similar data collected from the more basic drifting buoys deployed under the International Arctic Buoy Program (IABP; http://iabp.apl.washington.edu/). This information is also critical for extending the results from these individual sites to other regions of the Arctic (Perovich and RichterMenge, 2006).

\section{ICE MASS-BALANCE BUOY: INSTALLATION AND COMPONENTS}

In its current configuration, the IMB is designed to provide ice mass-balance measurements of undeformed, multi-year ice in the perennial ice zone. This restriction is primarily due to the fact that the IMB is not designed to float. Further, the instrumentation is not contained in one single package, and hence can pull apart if subject to ice deformation (Fig. 1).

Site selection is a critical aspect of the IMB deployment. To facilitate the extension of the data from a point measurement to a broader region, the buoy is placed in a representative undeformed, multi-year ice floe. A multi-year ice floe is recognized by a relatively uniform expanse of small hummocks, which are typically $<1 \mathrm{~m}$ high and extend over an area of at least tens of meters. By representative, we mean that the multi-year ice floe selected for a deployment site is of average size and thickness, relative to the region of study. This is typically determined from air reconnaissance flights and sample drillholes. Once a site is selected, the buoy is located near a hummock. Ridges and existing or remnant melt ponds are avoided, since the ice thickness at these locations is not representative. Placement near a hummock also facilitates data collection over multiple annual cycles, since these sites are more likely to survive the summer melt.

Figure 1 shows an IMB that has been deployed. The central component of the IMB is a $20.5 \mathrm{~cm}$ diameter, watertight aluminum tube, which houses the data collection and transmission systems and batteries. The main tube is installed with a $25.5 \mathrm{~cm}$ diameter ice auger, used to drill an 
approximately $1 \mathrm{~m}$ deep hole in the ice cover. The top of the tube serves as a platform for a satellite transmitter, a global positioning system (GPS) sensor and a barometer. The barometer measures SLP, with an accuracy of $0.1 \mathrm{hPA}$.

Other instruments are connected to the main tube by umbilical cords, including the thermistor string and acoustic sounders. The thermistor string consists of a series of $3 \mathrm{~cm}$ diameter, $1.5 \mathrm{~m}$ long PVC rods, with thermistors mounted at $10 \mathrm{~cm}$ intervals. Typically, three rods are linked together to form a $4.5 \mathrm{~m}$ long string. Temperatures measured by the thermistors are accurate to $0.1{ }^{\circ} \mathrm{C}$. The thermistor string is installed through a $5 \mathrm{~cm}$ diameter hole, drilled through the thickness of the ice cover. It is positioned in the ice so that the top thermistor is about $0.7 \mathrm{~m}$ above the ice surface. If the ice cover is $2.5 \mathrm{~m}$ thick, the thermistor string would extend another $1.3 \mathrm{~m}$ below the bottom of the ice cover. This installation configuration is designed to accommodate changes in the thickness of the ice cover during the course of multiple seasonal cycles, resulting in a change of the relative location of the thermistor string in the ice cover. Typically, after one melt cycle more of the top of the thermistor string will be exposed, while during the next growth cycle more of the bottom of the thermistor string will be incorporated into the ice cover.

Acoustic rangefinder sounders are located above and below the ice surface. The accuracy of both sounders is $5 \mathrm{~mm}$ and they must be at least $0.75 \mathrm{~m}$ from the ice to provide useful data. The above-ice sounder is mounted on an arm, whose base is placed in a $10 \mathrm{~cm}$ diameter hole. This hole is also drilled through the ice cover, so that the base will freeze into place. The arm is designed so that the distance between the above-ice sounder and ice surface is $1.5 \mathrm{~m}$. Thus, $0.75 \mathrm{~cm}$ of snow can accumulate before the minimum stand-off distance is reached. A thermistor, located in a shielded housing, is mounted to the above-ice sounder's support arm. This thermistor provides surface air temperatures with an accuracy of $0.1^{\circ} \mathrm{C}$. The below-ice sounder is positioned on a $5 \mathrm{~m}$ long rod, and is lowered under the ice cover, facing upward, through another $10 \mathrm{~cm}$ diameter hole. Ideally, the below-ice sounder is located at 1.5-2 $\mathrm{m}$ below the ice cover.

During the installation process, each time a hole is drilled through the thickness of the ice cover, measurements are taken of the ice thickness, ice freeboard and snow depth. These data provide the set of initial conditions and help confirm the validity of the initial set of measurements received from the buoy. If time permits, a more extensive survey of the ice thickness in the area is taken, either by drilling or using electromagnetic survey equipment (Eicken and others, 2001).

An Argos satellite antenna is mounted on the top of the main housing. Using the Argos polar-orbiting satellite system, data are transmitted from each IMB, on average, every $1-2$ hours. During each transmission the buoy location is recorded. The data collection and transmission systems are programmed to provide a full set of measurements every 2-12 hours, depending on specific programming protocols.

The IMB system is designed to support the measurement and transmission systems for up to 3 years. To date, the average life of a buoy has been about 1 year. Review of the buoy data records provides clues that help determine the reason for the end of an IMB's transmission. These reasons include melting of the ice, destruction due to ice dynamics or animal antics, or component failure.

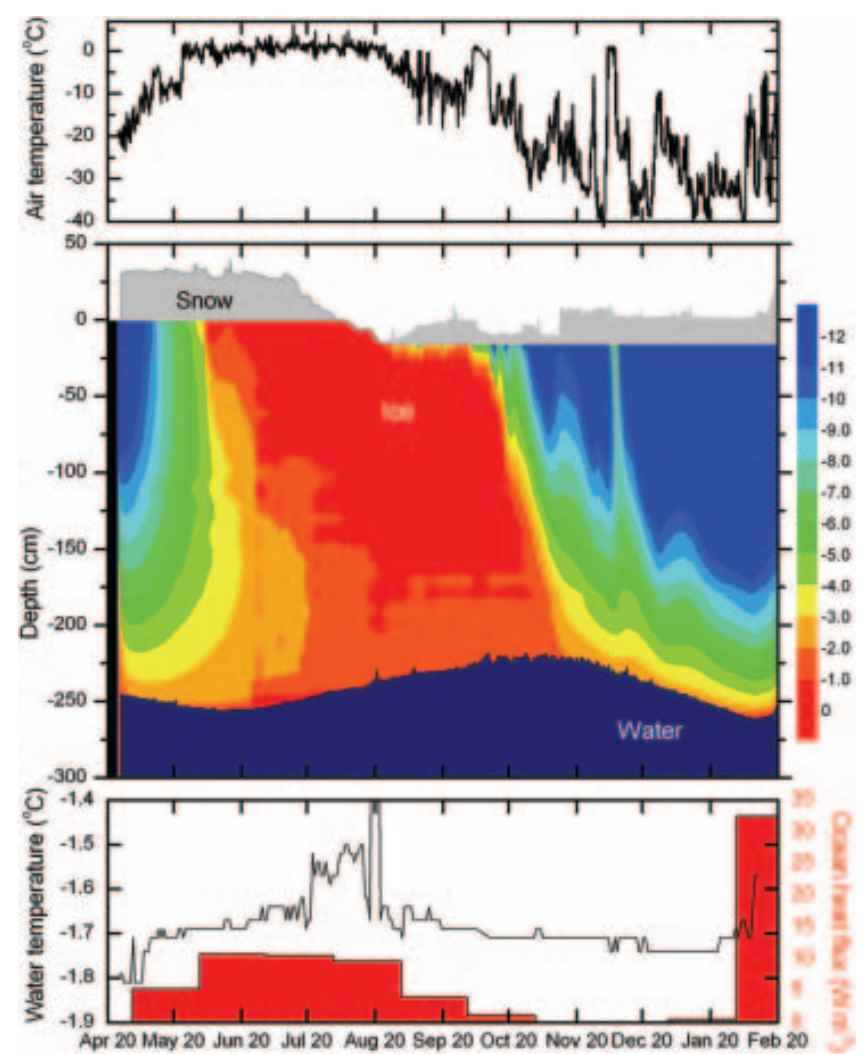

Fig. 2. Example of time-series data collected from an IMB, including air temperature; ice mass balance, delineated by changes in ice growth, surface melt, bottom ablation and snow accumulation; internal ice temperature fields; ocean water temperature near the bottom of the ice cover; and a temporally averaged estimate of ocean heat flux. This particular IMB (NPEO 21078; see Table 1) was deployed near the North Pole in April 2002, drifted with the ice cover through the Fram Strait, and melted out of the ice cover in February 2003 (see Fig. 3).

The IMB has been specifically designed for ease of deployment. Drilling holes, linking components and throwing a switch is all that is required for installation. The installation process typically takes $1-2$ hours. With this feature, an IMB can be deployed by anyone who has experience in Arctic operations. Hence, it allows us to maximize the opportunities for deployment by coordinating with other programs.

\section{RESULTS AND DISCUSSION}

An early version of the IMB was deployed in 1993, during the Sea Ice Mechanics Initiative (SIMI) field program (Perovich and others, 1997). Since then, we have deployed 32 buoys. The majority of these deployments occurred after 2000, when the IMB became routinely deployed as part of the North Pole Environmental Observatory (NPEO). There is another notable increase in the number of deployments in 2003, associated with the US National Oceanic and Atmospheric Administration's (NOAA) commitment to support a network of in situ ice-thickness measurement platforms.

Reflecting the availability of deployment platforms, there has been a concentration of buoy deployments in the vicinity of the North Pole and in the Beaufort Sea. These buoys are listed in Table 1, and Figure 3 shows their drift tracks. The influence of the general circulation of the sea-ice 


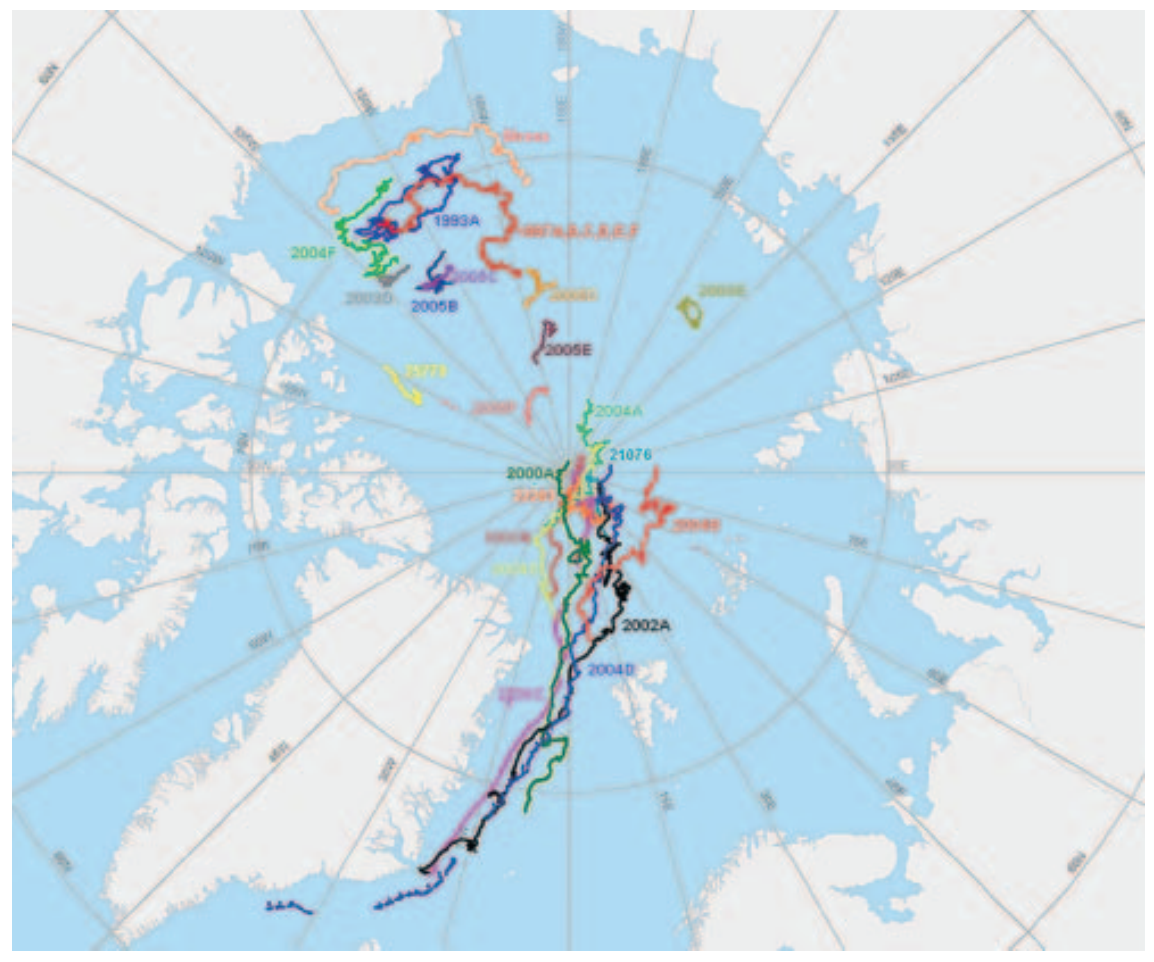

Fig. 3. Initial location and drift of IMBs deployed near the North Pole and in the Beaufort Sea, beginning in 1993.

cover is immediately evident from the drift tracks. Buoys deployed in the vicinity of the North Pole are affected by the transpolar drift and eventually transported out of the basin via Fram Strait. These buoys typically drift out of the Arctic basin 1-1.5 years after deployment. The drift tracks of the buoys deployed in the Beaufort Sea are more circuitous, reflecting the influence of the Beaufort Gyre. Depending on the strength of the gyre, the buoys either move in a circle within the basin (e.g. SIMI) or move toward the pole as they become incorporated into the Transpolar Drift (e.g. Surface Heat Budget of the Arctic (SHEBA)).

Data from each of the deployed buoys provide a detailed time series, characterizing the evolution of the ice cover. An example of these data is presented in Figure 2, where data from buoy NPEO 21078, deployed near the North Pole in April 2002, are shown. The time series ends in February 2003, when the ice melted as the buoy was transported to the ice edge through the Fram Strait. These data provide a wealth of information on air, ice and ocean properties. When combined, they tell the story of how and why the ice cover changes. In this particular case, the ice was $245 \mathrm{~cm}$ thick and the snow was $31 \mathrm{~cm}$ deep when the buoy was deployed. The ice thickness increased slightly, reaching a maximum of $255 \mathrm{~cm}$ in early June, when the bottom of the ice cover began to ablate. The depth of the snow cover remained relatively constant through June. Interestingly, while air temperatures reached the freezing point in midJune, rapid snowmelt did not begin until 11 July. A close examination of the temperature record shows a diurnal signal in the air-temperature record. In June, air temperatures were above zero at high solar elevations (noon) and below zero at low solar elevations (midnight). It was not until July that air temperatures were consistently above zero throughout the day, providing the conditions necessary for rapid snowmelt. This illustrates how, at high latitudes, the surface energy budget can hover near zero in the summer.
During this period, from mid-June to July, the ice cover reached a near-isothermal state. The ice surface, which was protected by the snow cover, did not begin to ablate until early August, when the snow cover was completely melted and the ice cover became exposed. Ablation of the top surface of the ice cover continued until late August, when air temperatures began to fall, marking the end of the surface melt season in this region of the Arctic. A total of $15 \mathrm{~cm}$ of ice was lost from the ice surface. Once the ice cover began to freeze up, snow quickly began to accumulate on the surface. Colder temperatures began penetrating the ice cover in waves that reflect the changes in the air temperature.

The ablation period at the bottom of the ice cover was significantly longer, with melting evident from early July until early November. The relative delay in freeze-up is due, in part, to the insulating effects of snow and ice cover, which slows and dampens the penetration of heat to the bottom ice surface. During the ablation period at the bottom of the ice cover, $28 \mathrm{~cm}$ of ice was lost, reducing the ice thickness to $225 \mathrm{~cm}$. Based on this mass loss, the average ocean heat flux from July through October was approximately $8 \mathrm{~W} \mathrm{~m}^{-2}$. The ice grew from early November until early February, when the ice was advected out of the basin. This transition is characterized by a rapid and significant increase in the ocean heat flux as the ice encounters the warm surface water at the ice edge.

A summary of data collected from the buoys deployed near the North Pole and in the Beaufort Sea is presented in Table 1. These data include initial ice and snow conditions, maximum snow depth and ice thickness, ice growth and ablation, and onset and end of melting. There are voids in the data due to component failure. We have not included in the table the eight IMBs deployed this summer (2005) since, at this writing, these buoys have been in the ice cover such a short time. A more complete dataset, including 
Table 1. Summary of data collected from IMBs deployed in the Beaufort Sea and in the vicinity of the North Pole, beginning in $1993 .\left(T_{\mathrm{i}}\right)_{0}$ is initial ice thickness, $G_{\mathrm{b}}$ is bottom growth, $M_{\mathrm{s}}$ is surface melt, $M_{\mathrm{b}}$ is bottom melt, $S_{\mathrm{s}}$ is start of snow surface melt, $l_{\mathrm{s}}$ is start of ice surface melt, and $l_{\mathrm{f}}$ is end of ice surface melt

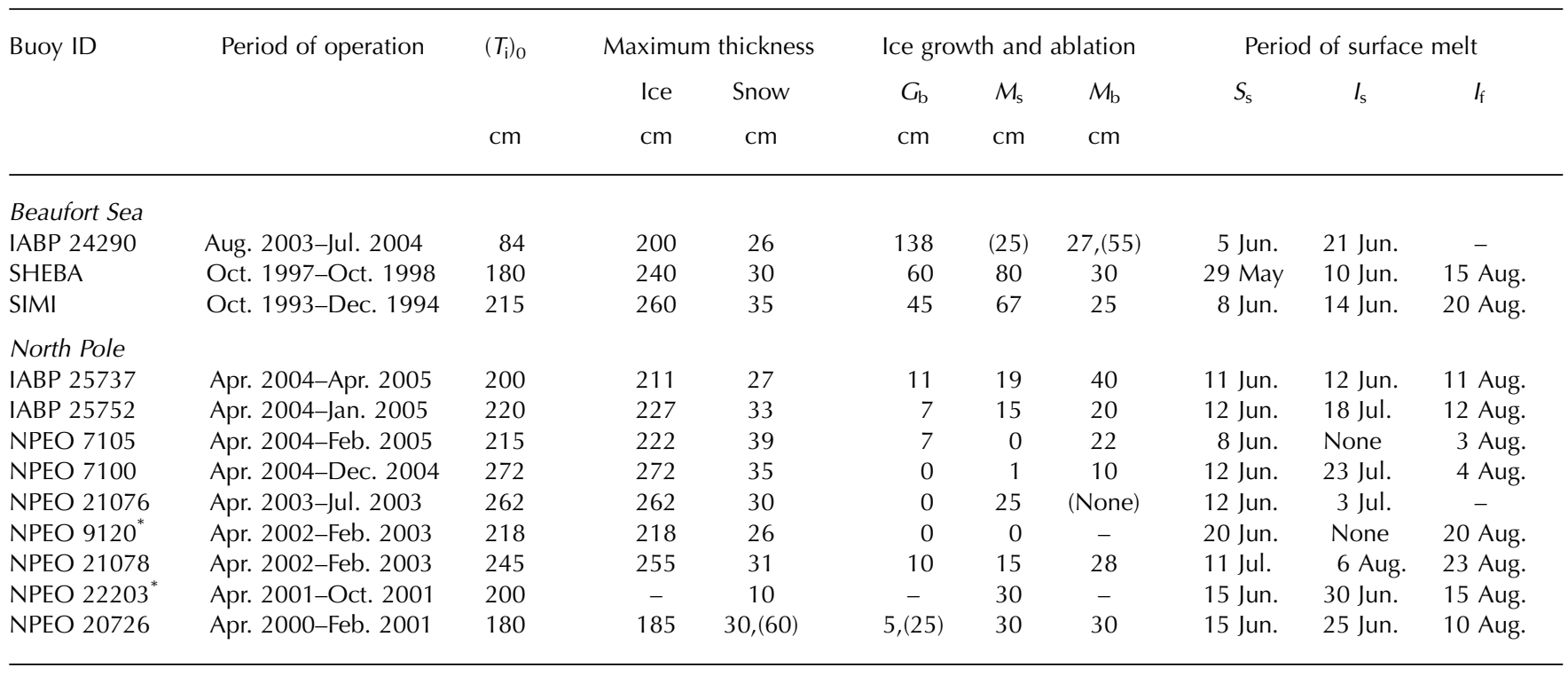

*Unable to retrieve full suite of measurements due to component failure.

( ) Last recorded measurement, occurring during a melt or growth phase.

buoys located in other regions of the Arctic, is available at the website: http://www.crrel.usace.army.mil/sid/IMB/ index.htm.

The effort to establish and maintain a network of IMBs is in its early stages. As more data are acquired, they can be used in conjunction with other information to examine both regional and interannual variability in the mass balance of the ice cover. Even at this early stage, regional characteristics are evident. The most pronounced difference is in ablation at the ice surface. At the North Pole buoys, ice surface ablation ranged from 0 to $30 \mathrm{~cm}$. At the Beaufort buoys the ice surface ablation ranged from 67 to $80 \mathrm{~cm}$. The difference of approximately $50 \mathrm{~cm}$ of surface melt between the Beaufort Sea and the North Pole represents an additional $150 \mathrm{MJ} \mathrm{m}^{-2}$ of energy input at the surface of the ice. Averaged over a 2 month long melt season, this is a substantial increase in the surface heat budget of $30 \mathrm{~W} \mathrm{~m}^{-2}$. This result is not surprising and is consistent with a longer period of ice surface melt observed at the Beaufort buoys (average of 76 days) compared to the North Pole buoys (average of 59 days). The longer period of melt at the Beaufort buoys is a function of the surface heat flux, which is greater at the comparatively lower latitudes. It is interesting to observe that the start of the surface melt period, as defined by the start of melt at the snow surface, is comparable in both locations, occurring approximately a week earlier at the IMBs in the Beaufort region. Similarly, the end of the surface melt period is about a week later at the Beaufort buoys. The greatest difference between these two regions is seen in the date when the snow cover is completely melted and the top of the ice surface begins to melt. This transition typically occurs in mid-June at the Beaufort buoys and, on average, in mid-July at the North Pole.

During the summers of 2002 and 2004, there was either no or very little melting at the top surface of the ice cover at the North Pole buoys. This was confirmed by images from a video camera that had also been located at these buoys as part of the NPEO. The absence of surface melt in the vicinity of the North Pole is in marked contrast to observations of the summer extent and area of the sea-ice cover, which reached a record minimum in 2002 and a near-record minimum in 2004 (Serreze and others, 2003; Stroeve and others, 2005).

Ablation at the bottom of the ice cover was spatially more consistent, ranging from 10 to $40 \mathrm{~cm}$ at the North Pole buoys and from 25 to $30 \mathrm{~cm}$ at the Beaufort buoys. The average maximum ice thickness and snow depth at the North Pole buoys and Beaufort buoys was also comparable. The maximum ice thickness at the North Pole buoys and the Beaufort buoys was 232 and $238 \mathrm{~cm}$, respectively. The IMBderived maximum thickness measurements of undeformed multi-year ice are comparable to the mean winter ice thickness in the Southern Beaufort Sea of $2.5 \mathrm{~m}$ estimated from satellite-based altimeters over the 8 year period 19932001 (Laxon and others, 2003). The average maximum snow depth was $27 \mathrm{~cm}$ at the North Pole buoys and $30 \mathrm{~cm}$ at the Beaufort buoys.

\section{CONCLUSIONS AND FUTURE WORK}

IMBs provide a useful and relatively simple tool for monitoring changes in the mass balance of the ice cover over multiple annual cycles. A unique characteristic of the IMB is the ability to determine whether the change occurs at the top or bottom surface of the sea-ice cover and, hence, to gain insight into the source of the change. This characteristic cannot be duplicated by any other autonomous measurement system currently available for measuring ice thickness, considering both in situ and remote platforms. The IMB is also distinguished by the high temporal resolution of the data it acquires, providing a full set of measurements every 2-12 hours. Among other things, this feature allows for the determination of the beginning and end of melt at the top and bottom surface of the ice cover.

Since 2000, IMBs have been deployed each spring from the NPEO and in several other areas including a few in the Beaufort Sea and Central Basin. At this point, the collective time series is too short to draw significant and specific 
conclusions regarding interannual and regional variability in ice mass balance. Comparisons of available data indicate that ice surface ablation is greater in the Beaufort region $(67-80 \mathrm{~cm})$, relative to the North Pole $(0-30 \mathrm{~cm})$, consistent with a longer period of melt in the more southerly location. Ablation at the bottom of the ice $(23 \mathrm{~cm})$, maximum ice thickness $(235 \mathrm{~cm})$ and maximum snow depth $(28 \mathrm{~cm})$ were comparable in the two regions.

The true value of the IMB is realized when it is coupled with other instruments. For instance, the IMB can be collocated with ice-based oceanic and atmospheric measurement systems to provide a complete profile of atmospheric, ice and upper-ocean properties. Towards this end, IMBs are regularly located at the NPEO (http://psc.apl. washington.edu/northpole/), used to augment the buoy network established and maintained by the IABP, and deployed as part of the Arctic research programs at the Japan Agency for Marine-Earth Science and Technology (JAMSTEC; Kikuchi and others, 2002) and at Woods Hole Oceanographic Institution, Woods Hole, MA, USA (WHOI; Kemp and others, 2005). Installing a network of drifting IMBs and moored ice-profiling sonar creates a complementary set of Eulerian and Lagrangian ice-thickness measurements. Based on the results presented in Lindsay and Zhang (2006) and building on the work of Melling and others (2005), we have augmented the IMB network by the deployment and maintenance of a moored, ice-profiling sonar, on the Chukchi Plateau. IMBs can be located in regions where submarine and helicopter-borne electromagnetic surveys are conducted to provide a temporal link between survey missions. Data from IMBs can be used to validate and calibrate remote-sensing tools, including satellite-based instrumentation design to measure ice thickness or the onset and end of surface melt. Numerical models can be improved by assimilating data from IMBs. Combined, these tools can provide the necessary comprehensive picture of changes in the mass balance of the Arctic sea-ice cover.

As currently designed, the IMB is best suited for deployment in the multi-year ice of the perennial ice zone. This is a significant limitation. One focus of our future work is to improve the versatility of the IMB, developing a system that is robust and can be placed in any ice type in both the perennial and seasonal ice zones. Another focus is the development of the associated website. The site will be upgraded to provide near-real-time data from IMBs that are actively reporting, and easy access to archival data. Our primary focus will be to continue efforts to coordinate the deployment of the IMB with other programs, with the intention of eventually seeing the IMB incorporated into an Arctic Ocean Observing System.

\section{ACKNOWLEDGEMENTS}

This work has been supported by the NOAA, the US National Science Foundation and the US Office of Naval Research. We acknowledge the gracious cooperation of many organizations and icebreakers which have assisted with the deployment of the autonomous IMBs.

\section{REFERENCES}

Comiso, J.C. 2002. A rapidly declining perennial sea ice cover in the Arctic. Geophys. Res. Lett., 29(20), 1956. (10.1029/ 2002GL015650.)
Eicken, H., W.B. Tucker, III and D.K. Perovich. 2001. Indirect measurements of the mass balance of summer Arctic sea ice with an electromagnetic induction technique. Ann. Glaciol., 33, 194-200.

Hanson, A.M. 1965. Studies of the mass budget of Arctic pack-ice floes. J. Glaciol., 5(41), 701-709.

Kemp, J., K. Newhall, W. Ostrom, R. Krishfield and A. Proshutinsky. 2005. The Beaufort Gyre Observing System 2004: mooring recovery and deployment operations in pack ice. Woods Hole, MA, Woods Hole Oceanographic Institution. (Tech. Rep. WHOI-2005-5.)

Kikuchi, T., K. Hatakeyama, K. Shimada, T. Takizawa and J. Morison. 2002. Oceanographic observation under multi-year ice of the Arctic Ocean using J-CAD. In 17th International Symposium on Okhotsk Sea and Sea Ice, 24-28 February 2002, Mombetsu, Japan. Proceedings. Sapporo, Institute of Low Temperature Science.

Kwok, R., H.J. Zwally and D. Yi. 2004. ICESat observations of Arctic sea ice: a first look. Geophys. Res. Lett., 31(16), L16401. (10.1029/2004GL020309.)

Laxon, S., N. Peacock and D. Smith. 2003. High interannual variability in sea ice thickness in the Arctic region. Nature, 425(6961), 947-950.

Lindsay, R.W. and J. Zhang. 2006. Arctic Ocean ice thickness: modes of variability and the best locations from which to monitor them. J. Phys. Oceanogr., 36(3), 496-506.

Maykut, G.A. and M.G. McPhee. 1995. Solar heating of the Arctic mixed layer. J. Geophys. Res., 100(C12), 24,691-24,703.

Melling, H., D.A. Riedel and Z. Gedalof. 2005. Trends in the draft and extent of seasonal pack ice, Canadian Beaufort Sea. Geophys. Res. Lett., 32(24), L24501. (10.1029/2005GL024483.)

Parkinson, C.L. and D.J. Cavalieri. 2002. A 21 year record of Arctic sea-ice extents and their regional, seasonal and monthly variability and trends. Ann. Glaciol., 34, 441-446.

Parkinson, C.L., D.J. Cavalieri, P. Gloersen, H.J. Zwally and J.C. Comiso. 1999. Arctic sea ice extents, areas, and trends, 1978-1996. J. Geophys. Res., 104(C9), 20,837-20,856.

Perovich, D.K. and B.C. Elder. 2001. Temporal evolution of Arctic sea-ice temperature. Ann. Glaciol., 33, 207-211.

Perovich, D.K. and J.A. Richter-Menge. 2006. From points to Poles: extrapolating point measurements of sea-ice mass balance. Ann. Glaciol., 44 (see paper in this volume).

Perovich, D.K., B.C. Elder and J.A. Richter-Menge. 1997. Observations of the annual cycle of sea ice temperature and mass balance. Geophys. Res. Lett., 24(5), 555-558.

Perovich, D.K., T.C. Grenfell, J.A. Richter-Menge, B. Light, W.B. Tucker, III and H. Eicken. 2003. Thin and thinner: ice mass balance measurements during SHEBA. J. Geophys. Res., 108(C3), 8050. (10.1029/2001JC001079.)

Rothrock, D.A., Y. Yu and G.A. Maykut. 1999. Thinning of the Arctic sea-ice cover. Geophys. Res. Lett., 26(23), 3469-3472.

Rothrock, D.A., J. Zhang and Y. Yu. 2003. The Arctic ice thickness anomaly of the 1990s: a consistent view from observations and models. J. Geophys. Res., 108(C3), 3803. (10.1029/ 2001JC001208.)

Serreze, M.C. and 9 others. 2003. A record minimum Arctic sea ice extent and area in 2002. Geophys. Res. Lett., 30(3), 1110. (10.1029/2002GL016406.)

Stroeve, J.C. and 6 others. 2005. Tracking the Arctic's shrinking ice cover: another extreme September minimum in 2004. Geophys. Res. Lett., 32(4), L04501. (10.1029/2004GL021810.)

Tucker, W.B., III, J.W. Weatherly, D.T. Eppler, D. Farmer and D.L. Bentley. 2001. Evidence for rapid thinning of sea ice in the western Arctic Ocean at the end of the 1980s. Geophys. Res. Lett., 28(9), 2851-2854.

Untersteiner, N. 1961. On the mass and heat budget of Arctic sea ice. Arch. Meteorol. Geophys. Bioklimatol., Ser. A., 12(2), 151-182.

Wadhams, P. and N.R. Davis. 2000. Further evidence of sea ice thinning in the Arctic Ocean. Geophys. Res. Lett., 27(24), 3973-3976. 